\title{
Ethos crítico y a priori histórico de una experiencia posible. Contribución filosófica a la noción de crítica desde una ontología del presente
}

\author{
Silvana Vignale ${ }^{1}$ \\ INCIHUSA CONICET - Argentina
}

Revista Derechos en Acción ISSN 2525-1678/ e-ISSN 2525-1686

Año 5/N 14, Verano 2019-2020 (21 diciembre a 20 marzo), 858-882

DOI: https://doi.org/10.24215/25251678e380

ORCID: https://orcid.org/0000-0002-2003-5628

Tal como lo anticipa el título de este dossier, la crítica se concibe como el trabajo sobre los límites y las posibilidades de un determinado objeto. Nuestra contribución se ocupará de atender el carácter de la crítica desde una perspectiva filosófica, más específicamente, desde el trabajo filosófico de una ontología del presente. Para eso, la abordaremos en un primer momento como una metódica de la investigación en las ciencias sociales y humanas, tomando distancia del disciplinamiento que busca reducir el trabajo teórico a metodologías prefabricadas. El posicionamiento crítico involucra al investigador en la realidad que investiga, e historiza su emergencia junto al objeto de estudio, con atención a las implicancias entre saber y poder, en el marco de lo que podemos denominar una epistemología crítica. Es desde esto último que es relevante la contribución de Michel Foucault, en cuanto desplaza el a priori objetivo y formal kantiano a un a priori subjetivo e histórico. Y eso mediante un

1 Docente en la Universidad Nacional de Cuyo, Universidad Nacional de Lanús, Universidad del Aconcagua, investigadora del CONICET Mendoza. 
ejercicio del pensamiento que busca problematizar a la política, o como lo veremos ya hacia el final de nuestro escrito, como el cultivo de la virtud o el arte de la inservidumbre voluntaria y de la indocilidad reflexiva, que apunta a cuestionar las relaciones entre verdad y poder y a mostrar las implicancias de un sujeto que se resiste a ser gobernado de una determinada forma, abriéndose al plano de lo ético, y pasando por lo tanto de una metódica o actitud del trabajo teórico a un ethos o actitud práctica, vinculada a los modos de vida y a los propios procesos de subjetivación.

\section{La crítica como método de trabajo teórico}

La idea de la crítica como definición de los límites y posibilidades del objeto se remonta a Immanuel Kant en el siglo XVIII, en respuesta a una de las preocupaciones de la época relativas a cómo conocemos. En su enorme trabajo plasmado en la Crítica de la razón pura, definió los alcances de la crítica para la metafísica (Kant, 2008). Con una actitud de vigilancia epistemológica entre el dogmatismo al que conduce el racionalismo cartesiano y el escepticismo que acarrea el empirismo de David Hume, elaboró una tercera posición que equilibró la respuesta a la pregunta por las fuentes del conocimiento. Así, la crítica aparece como el ejercicio por establecer los límites de la razón y sus condiciones de posibilidad para el conocimiento objetivo. Esta vigilancia es también una denuncia a los tropiezos de la metafísica, por haber procedido por meros tanteos, alzándose por encima de las enseñanzas de la experiencia -al pretender tomar como objetos de conocimiento a ideas puras de la razón (Dios, alma, mundo)-, de las cuales no tenemos correlato empírico, por lo tanto, noúmenos que podemos pensar, pero no conocer. Hay, en consecuencia, un esfuerzo de Kant respecto al lugar del sujeto en el proceso del conocimiento, introduciendo en la historia del pensamiento un giro copernicano -tal como él mismo lo designó- al demostrar que no son los objetos los que determinan el conocimiento, sino la estructura trascendental 
del sujeto, esto es lo que el sujeto "pone" en términos de formas y estructuras a priori, mediante las facultades de la sensibilidad y del entendimiento. En este marco, la metafísica para llegar a ser ciencia debiera poder determinar a priori su objeto, es decir, independientemente de la experiencia es posible saber qué es objeto o no de conocimiento para la razón atendiendo a la estructura trascendental del sujeto.

Este acontecimiento, mencionado aquí brevemente, dejó importantes andamios para el trabajo filosófico, no sólo en materia de una gnoseología, sino como herramienta para los modos en que ejercemos el pensamiento, es decir, como metódica para el trabajo filosófico. No obstante, esto no significa que haya una sola manera de ejercer la crítica, ni que la misma pueda reducirse a una consecución de estrategias tal como suele pensarse la cuestión del método.

Desde un punto de vista estrictamente metodológico, se suele encorsetar el trabajo de investigación de las ciencias sociales y humanas sólo dentro de los modelos cualitativos y cuantitativos (y sus mixturas), forzando muchas veces el problema de investigación a metódicas prefabricadas, en cuanto se antepone el método al tipo de problema en cuestión.

Por otra parte, la relación sujeto-objeto que domina desde la modernidad el ámbito del conocimiento, encuentra su mejor partenaire en la neutralidad valorativa, y como sujetos nos ha colocado no sólo por fuera de la realidad que buscamos estudiar -posición epistemológica coherente a la denominada "concepción heredada" del Círculo de Viena, de carácter formalista y pretendidamente a-histórica (y cuya posición comprende el conocimiento científico como si fuera un espejo que refleja el mundo)-, sino que también esa posición epistemológica acarrea consecuencias ético-políticas, en cuanto desconoce la relación existente entre la "verdad" y las relaciones de poder.

Por eso, si en alguna medida de lo que se trata es de sensibilizar el trabajo teórico, eso es posible mediante una epistemología ampliada a lo histórico social, perspectiva que concibe que la producción del conocimiento no se encuentra al margen 
de los procesos históricos de conformación de las ciencias y sus objetos de estudio, de los problemas que se suscitan en una sociedad determinada, de las estrategias políticas y de los intereses económicos en juego, donde la objetividad (y, en definitiva, la verdad) no se define por la supuesta universalidad, sino por el producto de consensos y acuerdos científicos. En otras palabras, se trata de considerar el juego de fuerzas en un determinado campo de relaciones de poder, que intervienen en los procesos de investigación. Posición esta última más relacionada a la tradición francesa o epistemología crítica, en la que el sujeto no se posiciona "afuera" de la realidad que estudia, sino, por el contrario, se concibe formando parte de la misma. ${ }^{2}$

Estas reflexiones metodológicas se orientan a comprender a la crítica como una metódica del trabajo teórico, en el campo de una epistemología ampliada hacia lo histórico social. Aunque no se reduce a ella, puesto que, en cuanto comporta la posibilidad de una transformación subjetiva -como veremos en adelante-, involucra una ampliación no sólo a lo histórico social, sino también a lo ético. Cuando decimos "ética" aquí, no aludimos a la disciplina que reflexiona sobre los comportamientos morales, sino a la posibilidad de autodeterminación subjetiva, al trabajo que el sujeto realiza sobre sí mismo en su propia configuración. Eso no es otra cosa que admitir que en todo proceso de construcción del conocimiento hay también procesos de construcción subjetiva, asunto al que nos hemos dedicado en otros trabajos (Vignale, 2017b). Dicho de otra manera, objeto y sujeto se constituyen en un mismo campo de fuerzas, y eso nos invita a elaborar las herramientas de estudio en cada caso, los modos o las estrategias a partir de las cuales podemos acercarnos al objeto sin forzarlo con a priori metodológicos.

El trabajo crítico -en un sentido amplio- atiende a todo lo que aquí venimos sosteniendo: no abstraer al objeto de la

\footnotetext{
2 Sobre las diferentes posiciones epistemológicas, cfr. SAMAJA, Juan (2000). Semiótica y Dialéctica, Buenos Aires, JVE. Y Díaz, Esther (2000). La posciencia. El conocimiento científico en las postrimerías de la modernidad. Buenos Aires, Biblos.
} 
realidad mediante el fórceps de los métodos, tampoco de su tiempo histórico y de su contexto de surgimiento, y además no abstraer al sujeto de la realidad que investiga, y comprender en qué medida la crítica no es sólo el trabajo teórico de conocer los límites y posibilidades del objeto, sino también las posibilidades indefinidas de transformación subjetiva, aspecto que abordaremos más adelante a partir del pensamiento de Foucault. ${ }^{3}$ En otras palabras, hay trabajo crítico cada vez que se atiende el carácter histórico y político de determinado objeto de estudio, así como la pertenencia del sujeto a esa realidad que investiga. En esta dirección es que Didier Eribon apunta:

El análisis de los determinismos históricos y sociales, por un lado, y el rechazo de las trascendencias, los trascendentales o los casi trascendentales, por otro (...) delimitan a mi entender el campo del pensamiento crítico, si se considera este como el lugar donde se anudan a la vez los hilos de un proceder histórico y político que se asigna como horizonte -jamás alcanzado- el ideal de una democracia radical y que, por consiguiente, aspira a estar siempre abierto a la llegada del acontecimiento, de lo inédito, atento al porvenir contenido y anunciado lo que se mueve en el presente, a las líneas de fractura que se dibujan en él y, por lo tanto, al presente acorde a la forma y el sentido que ya le confiere el porvenir hacia el que tiende (2019, p. 12).

Teniendo en cuenta que las investigaciones de Foucault son fundantes respecto de un modo de realizar el trabajo crítico, en abandono de todo uso de universales y de una concepción tradicional del poder fundado sobre modelos jurídicos e

\footnotetext{
3 A propósito de la posición de una epistemología crítica que supone que el sujeto no se encuentra por fuera de la realidad que estudia, y de la cuestión de la superación de la dicotomía entre teoría y praxis, hemos abordado recientemente en una publicación en la Revista Bordes, Ciencias sociales y principio de incertidumbre, las consecuencias políticas del trabajo en ciencias sociales y humanas. A partir de una reflexión en torno al texto de Agamben ¿Qué es real? (Adriana Hidalgo, 2019), sostenemos que el investigador interviene "conduciendo el fenómeno en cierta dirección", en una suerte de "gobierno de los fenómenos sociales". Cfr. https://revistabordes.unpaz.edu.ar/ciencias-sociales-y-principio-de-incertidumbre/
} 
institucionales (el derecho, el Estado, la teoría de la soberanía), y en favor de un análisis de los dispositivos concretos a través de los cuales el poder penetra en los cuerpos mismos de los súbditos y gobierna sus formas de vida (Agamben, 2018, p. 19), abordaremos a continuación la concepción de una crítica desde una ontología del presente, a partir de algunas herramientas ofrecidas por el pensador francés.

\section{La crítica como a priori histórico de una experiencia posible}

Dijimos que nuestra contribución a la noción de crítica se haría desde un enfoque filosófico, y más precisamente desde una ontología del presente. Realizar un diagnóstico del presente o una ontología histórica de nosotros mismos requiere trazar una genealogía que permita responder a la pregunta ¿cómo hemos llegado a ser los que somos? Se trata de una formulación tardía en el pensamiento foucaulteano, pero que ayuda a comprender la temporalidad en la que se inscribe el trabajo crítico como ethos filosófico, como "una prueba histórico-práctica de los límites que podemos franquear y, por consiguiente, como el trabajo de nosotros mismos sobre nosotros mismos en nuestra condición de seres libres" (Foucault, 2010c, 987).

Foucault concibió su propio trabajo como una historia crítica del pensamiento. En un texto firmado con el pseudónimo de Maurice Florence (una entrada para el Dictionnaire des philosophes, a cargo de D. Huisman, titulada "Foucault"), define al "pensamiento" como el acto que plantea, en sus diversas relaciones posibles, un sujeto y un objeto. De manera que "una historia crítica del pensamiento sería un análisis de las condiciones en las que se han formado o modificado ciertas relaciones entre sujeto y objeto, en la medida en que éstas constituyen un saber posible" (2010a, p. 999). Y aunque se adscriba a la tradición crítica de Kant, sin embargo, toma distancia de la idea de crítica como sola determinación las condiciones formales y empíricas del objeto para ser conocido. En una operación de 
desplazamiento, Foucault inscribe la crítica no en las condiciones de posibilidad del objeto, sino del sujeto, con atención a su emergencia, a su aparición, y a la posibilidad de su transformación. Puede recordarse el pasaje ya célebre de La verdad y las formas jurídicas, unos años antes de esta entrada al diccionario, cuando Foucault decía:

Mi objetivo será mostrarles cómo las prácticas sociales pueden llegar a engendrar ámbitos de saber que no solamente hacen aparecer nuevos objetos, conceptos nuevos, nuevas técnicas, sino que además engendran formas totalmente nuevas de sujetos y de sujetos de conocimiento. El propio sujeto de conocimiento también tiene una historia, la relación del sujeto con el objeto, o más claramente, la verdad misma tiene una historia (2010d, p. 488).

El fragmento revela algo muy propio del trabajo foucaulteano: no partir de universales, como primera precaución metodológica (en este caso, el sujeto de conocimiento), sino más bien mostrar el entramado histórico y político en el que se constituyen los saberes, y que dan lugar no solamente a determinados objetos de estudio (la locura, la criminalidad, la sexualidad), sino a la aparición de determinadas formas de ser sujeto. En esta "inversión" de perspectiva para el análisis -puesto que en lugar de suponer la verdad para hacer derivar de ella la necesidad de determinado ejercicio del poder, Foucault parte del análisis del funcionamiento del poder, para demostrar cómo los saberes surgen justificando a las prácticas- ya no se parte de un sujeto universal que, gracias a su racionalidad, tiene acceso a una verdad también universal. Por eso es importante comprender que la objetivación (el modo en que determinado objeto se vuelve un objeto de conocimiento) y la subjetivación (los modos de ser sujeto) no son independientes entre sí. Una historia crítica del pensamiento no es, entonces, "el descubrimiento de las cosas verdaderas, sino las reglas según las cuales, respecto de ciertos asuntos, lo que un sujeto puede decir depende de la cuestión de lo verdadero y de lo falso" (Foucault, 2010a, p. 1000), es decir, de formas de veridicción: 
la historia crítica del pensamiento no es ni una historia de las adquisiciones ni una historia de las ocultaciones de la verdad; es la historia de la emergencia de los juegos de verdad: es la historia de las "veridicciones», entendidas como las formas según las cuales se articulan, en un dominio de cosas, discursos susceptibles de ser llamados verdaderos o falsos: cuáles han sido las condiciones de esta emergencia, el precio que, en alguna medida, ésta ha pagado, sus efectos en lo real y el modo en que, ligando cierto tipo de objeto a determinadas modalidades del sujeto, dicha emergencia ha constituido, para un tiempo, para un área y para individuos dados, el a priori histórico de una experiencia posible (Foucault, 2010a, p. 1000).

El fragmento es elocuente para comprender que la tarea crítica no es aquella que supone una verdad absoluta, sino que toda objetividad es producto de lo que en un determinado discurso adquiere el carácter de verdad y/o falsedad, y al mismo tiempo, cómo se entraman objetivaciones y subjetivaciones en el marco de una "experiencia posible"; "experiencia posible" que adquiere una connotación diferente a la pura posibilidad de un objeto para el conocimiento teórico y que queda remarcado por el carácter bistórico que Foucault brinda a ese nuevo a priori.

El a priori histórico de una experiencia posible incluye también a la experiencia propia de un sujeto en relación a una verdad. Para decirlo con sus palabras, la "subjetividad" es entendida como "la manera en que el sujeto hace la experiencia de sí mismo en un juego de verdad en el que tiene relación consigo mismo" (Foucault, 2010a, p. 1000), cuestión no poco relevante respecto del carácter político de otra filosofía crítica, la que surge del desplazamiento de las condiciones y los límites de un conocimiento del objeto a "las condiciones y posibilidades indefinidas de transformación del sujeto" (Foucault, 2001, p. 497), y que como ethos o modo de vida se presenta como el ejercicio de resistencia que el sujeto puede realizar, en un acto de desujeción de determinado juego de verdad, como veremos enseguida. 
Pero detengámonos un momento sobre la noción de "experiencia", a propósito de la idea de "experiencia posible" a la que alude el pensador francés, que no es la misma que la de Kant. Foucault refiere con ella el carácter intrincado de las relaciones entre formas de veridicción, procedimientos de gubernamentalidad y formas de relación de sí consigo, que estructuran un determinado campo, y por lo tanto, no tiene un carácter personal o privado, tal como lo expresa Thomas Lemke:

The term experience is decisive in this context. It first indicates the relational and collective dimension of critique. Experiencia in Foucault's terminology is not something private or personal, but points to a collective practice defined by "the correlation between fields of knowledge, types of normativity, and forms of subjetivity in a particular culture". Thus, the ethos of critique Foucault envisions is not a solitary attitude or a mode of individual self-fashioning; it is closely connected to existing forms of government (2012, p. 65). ${ }^{4}$

Ahora bien, la importancia política de esta filosofía crítica es la de efectuar un análisis acerca de la aceptación o el rechazo de la propia actualidad, con lo cual la crítica es una metódica que no solamente tiene consecuencias teóricas, sino prácticas.

Como se ve, esto trae como consecuencia que la crítica se ejercerá no ya en la búsqueda de estructuras formales que tienen valor universal, sino como investigación histórica a través de los acontecimientos que nos han conducido a constituirnos y a reconocernos como sujetos de lo que hacemos, pensamos y decimos. En este sentido, esta crítica no es trascendental, y no tiene como fin hacer posible una metafísica: es una crítica genealógica en su

\footnotetext{
4 “El término experiencia es decisivo en este contexto. En primer lugar, indica la dimensión relacional y colectiva de la crítica. La experiencia, en los términos de Foucault, no es algo privado o personal, sino que apunta a una práctica colectiva definida por "la correlación entre campos de conocimiento, tipos de normatividad y formas de subjetividad en una cultura particular". Por lo tanto, el ethos de la crítica que Foucault imagina no es una actitud solitaria 0 un modo de auto-póiesis individual; está estrechamente relacionado con las formas de gobierno existentes" (la traducción es nuestra).
} 
finalidad y arqueológica en su método. Arqueológica -y no trascendental- en la medida en que no pretenderá extraer las estructuras universales de todo conocimiento o de toda acción moral posible, sino que buscará tratar los discursos que articulan lo que pensamos, decimos y hacemos, como otros tantos acontecimientos históricos. Y esta crítica será genealógica en el sentido en que no deducirá de la forma de lo que somos lo que nos es posible hacer o conocer, sino que extraerá de la contingencia que nos ha hecho ser lo que somos la posibilidad de ya no ser, hacer o pensar lo que somos hacemos o pensamos (Foucault, 2010c, p. 986).

No nos detendremos en este momento sobre la cuestión metodológica de la arqueología y la genealogía, aspectos que hemos abordado en otras oportunidades (Vignale, 2017b). Queremos subrayar lo que se presenta de modo claro respecto de la crítica: que ya no se trata de cómo la metafísica puede alcanzar el estatuto de una ciencia, la crítica histórica sobre la que trabaja Foucault "busca relanzar tan lejos y tan ampliamente como sea posible el trabajo indefinido de la libertad" (2010c, p. 986). 5 Es, como ya se ha dicho, el desplazamiento de un analítica de la verdad -que está atenta a las condiciones formales del conocimiento- hacia una ontología crítica del presente, es decir, hacia la búsqueda de las condiciones históricas de las relaciones entre sujeto y objeto.

\section{El ejercicio de problematización}

¿Qué ejercicio es el de la crítica? Una primera respuesta debe dirigirse a despejar qué cosa no es. Por ejemplo, no se trata de aquella forma de rechazo reducido a la descalificación

5 La noción de "libertad" aquí no debiera confundirse con la de las libertades formales, sino en orden de lo que Foucault Ilama las "practicas de libertad". Sobre esta diferencia hemos trabajado junto a Luciana Alvarez en: VIGNALE, Silvana y Luciana Alvarez (2018). Prácticas de libertad en la gubernamentalidad neoliberal: claves para pensar la desobediencia en los bordes del sujeto. XI Coloquio Internacional Michel Foucault "Foucault e as praticas da libertade" (Florianópolis, 2018). 
o análisis lapidario sólo en pos del descrédito. El ejercicio de la crítica no es tampoco el de la polémica, donde quien polemiza no renuncia a los propios privilegios de su lugar (dogmático) de enunciación, ni es el análisis de una cantidad de soluciones recusables, a excepción de una que sería la "buena" o la "correcta". La crítica no tiene tanto que ver con una recusación per se, o con el análisis de soluciones, sino con la posibilidad de plantear un problema. Foucault define este trabajo con el nombre de "problematización" (2010b).

El ejercicio de problematizar es relativo a un modo de abordar las cuestiones de la política: interpelar a la política sobre sus discursos de verdad, cuestionarla respecto de la emergencia de determinados objetos y sujetos; por ejemplo, en asuntos relativos a la cuestión de la delincuencia y la penalidad, hay razones para interrogar a la política sobre ellos, al menos para sospechar que su relación se reduzca a la prevención del crimen y a su castigo. En esta dirección, elaborar un dominio de hechos en torno a las prácticas y a los discursos sobre ellas, supone atender el anudamiento de tres ámbitos: el ámbito de la ciencia, el de la política y el de la ética. En otras palabras: la crítica se ocupa de problematizar desde el anudamiento e interferencia entre el ámbito donde se constituye algo como verdad -y se legitima como discurso verdadero-, el ámbito de ejercicio del poder -las prácticas concretas a partir de las cuales se ordena un determinado espacio-, y los modos de producción subjetiva -las formas de individuación y de ser sujetos-.

Sobre la implicancia de estos tres ámbitos y a modo de ejemplo, Foucault dice que con su trabajo en torno a la delincuencia

se trataba de ver qué estrategia política, dando su estatuto a la criminalidad, pudo apelar a ciertas formas de saber y a ciertas actitudes morales. Era cuestión asimismo de ver cómo estas modalidades de conocimiento y estas formas de moral pudieron reflejar y modificar estas técnicas disciplinarias (2010b, p. 995). 
Y señala un poco más adelante que en los dominios de su investigación sobre la locura, la delincuencia y la sexualidad ha privilegiado, en cada ocasión, un aspecto particular,

el de la constitución de una objetividad, el de la formación de una política y de un gobierno de sí, y el de la elaboración de una ética y de una práctica de sí mismo. Pero también he tratado cada vez de mostrar el lugar que en ello ocupan los otros dos componentes que son necesarios para la constitución de un campo de experiencia. En el fondo, se trata de diferentes ejemplos en los que se encuentran implicados los tres elementos fundamentales de toda experiencia: un juego de verdad, relaciones de poder y formas de relación con uno mismo y con los otros (2010b, p. 996).

En definitiva, el trabajo crítico, con lo que hemos repasado aquí, es el trabajo que elabora las condiciones -ciertos obstáculos o problemas en torno a las prácticas- a partir de las cuales determinadas soluciones se hacen posibles o determinadas respuestas tienen lugar. Como método, Foucault lo define como "un movimiento de análisis crítico mediante el cual se procure ver cómo se han podido construir las diferentes soluciones a un problema; pero también, cómo estas diferentes soluciones se desprenden de una forma específica de problematización" (2010b, p. 997).

De modo que aquella historia crítica del pensamiento es una historia de las problematizaciones, y no una historia de las ideas, postura que ya había sentado en La arqueología del saber (2004). ${ }^{6}$ Mientras la historia de las ideas es una historia de las representaciones, la historia crítica del pensamiento es una historia de las problematizaciones. No es tampoco una historia de los comportamientos, en cuanto el pensamiento no es lo que habita las conductas y les da sentido, sino

6 Cfr. el capítulo Arqueología e historia de las ideas, en: FOUCAULT, Michel (2004). La arqueología del saber. Buenos Aires, Siglo XXI, pp. 227-235. 
lo que permite tomar distancia con relación a esta manera de hacer o de reaccionar, dársela como objeto de pensamiento e interrogarla sobre sus sentidos, sus condiciones y sus fines. El pensamiento es la libertad con respecto a lo que se hace, el movimiento mediante el cual nos desprendemos de ello, lo constituimos como objeto y lo reflejamos como problema (Foucault, 2010b, p. 996).

De ahí la importancia de lo que fue expresado al comienzo del tomo segundo de La historia de la sexualidad: no reafirmar lo que ya sabemos, sino buscar los modos en que podemos pensar de otra manera, "no la que busca asimilar lo que conviene conocer, sino la que permite alejarse de uno mismo" (Foucault, 2008 , p. 14). Sobre este "alejamiento de uno mismo" o desujeción quisiéramos referirnos a partir de ahora, en la medida en que constituye una forma de ethos.

\section{El ethos crítico: desujeción de una política de la verdad}

Hemos hablado de la posibilidad de determinar las condiciones para una experiencia posible, experiencia histórica que se conforma por el entretejido entre formas de veridicción, técnicas de gubernamentalidad y técnicas de sí, entendidas estas últimas como

las prácticas sensatas y voluntarias por las que los hombres no solo se fijan reglas de conducta, sino que buscan transformarse a sí mismos, modificarse en su ser singular y hacer de su vida una obra que presenta ciertos valores estéticos y responde a ciertos criterios de estilo (Foucault, 2008, p. 17).

En las investigaciones de Foucault de sus últimos años pasó del estudio de una genealogía del poder a una crítica del sujeto, cuyo resultado fueron los tomos de la Historia de la sexualidad, aunque en gran medida encontramos muchas de sus definiciones más sustanciales de este periodo en los cursos dictado en el Collège de France desde 1980 a 1984. Como hemos mostrado en otro escrito, hay en este periodo la búsqueda de una ética 
como estructura vigorosa de la existencia, sin ninguna relación con lo jurídico per se, con un sistema autoritario o estructura disciplinaria (Vignale, 2013). Con esto se abre una dimensión ethopoiética del trabajo foucaulteano, relativa a los procesos de subjetivación y a formas de resistencia al poder político que en gran medida se centran en las relaciones entre el gobierno de sí y el gobierno de los otros. Ahora bien, esta dimensión ethopoiética hace que la crítica no solamente constituya un método de trabajo teórico. El ejercicio de otra filosofía crítica tiene alcances políticos: pone en cuestión el sujeto que somos, e interviene en su transformación, en cuanto su propio ejercicio involucra la formación de un ethos o modo de vida.

Creo que hay con ello la posibilidad de hacer una historia de lo que hemos hecho y que sea al mismo tiempo un análisis de lo que somos; un análisis teórico que tenga un sentido político; me refiero a un análisis que tenga sentido para lo que queremos aceptar, rechazar, cambiar de nosotros mismos en nuestra actualidad. Se trata, en suma, de salir en búsqueda de otra filosofía crítica: una filosofía que no determine las condiciones y los límites de un conocimiento del objeto sino las condiciones y posibilidades indefinidas de transformación del sujeto (Foucault, 2001, p. 497). ${ }^{7}$

Esta dimensión no deja de entrelazarse a otro de los asuntos que más interesan a Foucault, realizar una historia del presente, una ontología histórica de nosotros mismos. Su inscripción en la tradición crítica de Kant es en gran medida porque identifica en ella por primera vez planteada la pregunta por la actualidad: ¿qué es este presente del que formamos parte?

Hay tres trabajos relevantes donde Foucault aborda de forma directa la cuestión de la crítica, y en todos ellos su interés

7 El texto es extraído del escrito preparatorio para la conferencia "Sexualité et solitude", citado por Frédéric Gros en la "Situación del Curso" de La hermenéutica del sujeto. Cfr. FOUCAULT, Michel. La hermenéutica del sujeto. Curso en el Collège de France1981-1982. Buenos Aires, Fondo de Cultura Económica, 2001, p. 497. 
es problematizar acerca del vínculo entre la interrogación filosófica por el presente, el modo de ser histórico y la constitución de sí mismo. El primero es una conferencia en 1978, en la Société Française de Philosophie. El segundo y el tercero son trabajos en los que se dedica a analizar el texto de Kant ¿Qué es la ilustración?: la clase introductoria del curso El gobierno de sí $y$ de los otros, en el Collège de France, y una nueva versión del mismo texto que aparece en 1984, en un volumen en Estados Unidos, bajo la dirección de Paul Rabinow, respectivamente; textos de los que nos hemos ocupado recientemente a propósito de repensar la cuestión de la crítica en el marco de la gubernamentalidad neoliberal (Vignale, 2017a, 2018). En los tres, la crítica es caracterizada bajo la forma de una actitud o ethos, y muestra esta nueva relación con la historia que -sin dejar de lado la arqueología y la genealogía- completa metodológicamente un modo de abordar su objeto de estudio para ofrecer una problematización con atención a una inquietud política por el presente. Nos ocuparemos aquí, a los fines de este escrito, sobre el primero de este grupo de textos, conferencia que además se intitula, propiamente ¿Qué es la crítica? (Crítica y Aufklärung).

Como veníamos sosteniendo, la crítica plantea problemas a la política, o dicho ya en otros términos, la crítica se encuentra ligada al problema del gobierno, ¿en qué sentido? La conferencia presenta a la actitud crítica como una forma de resistencia política a determinada forma de gubernamentalidad, como una "voluntad de no ser gobernados de esta manera". Por lo tanto, Foucault encuentra más allá de la empresa kantiana y de las pequeñas actividades polémico-profesionales, que ha habido en la modernidad de Occidente una cierta manera de pensar, de decir y de actuar, "cierta relación con lo que existe, con lo que se sabe, con lo que se hace, una relación con la sociedad, la cultura, una relación, asimismo, con los otros, y que podríamos llamar, digamos, la actitud crítica" (Foucault, 2018, p. 46).

Posteriormente, en el dictado del curso de El gobierno de sí $y$ de los otros, Foucault retomará la cuestión de la actitud crítica como un resurgimiento de la parrbesía antigua, en el que ya se 
podía encontrar el vínculo complejo entre "política" y "verdad" (2009). Pero aquí esa relación se inscribe a partir del análisis de la pastoral cristiana, y de su desplazamiento en los siglos XV y XVI de la preocupación acerca de cómo gobernar a los otros, del ámbito religioso, al ámbito político o institucional: cómo gobernar el Estado, cómo gobernar una casa, cómo gobernar el cuerpo, cómo gobernar a los niños. Ahora bien, el interés de Foucault se encuentra en que esta preocupación no puede ser disociada de otra que aparece en la misma época, que es la de "¿cómo no ser gobernado?".

Cómo no ser gobernado que no debe comprenderse como una voluntad de no ser gobernado de ninguna manera, o en absoluto, actitud más anárquica cuyo objetivo es el volverse radicalmente ingobernable. Sino de "cómo no ser gobernado de esa manera, por esas personas, en nombre de esos principios, en vista de determinados objetivos y por medio de determinados procedimientos, no de esa manera, no para eso, no por esas personas" (Foucault, 2018, p. 49). Esta actitud insubordinada, este principio de desobediencia, es la "actitud crítica". Actitud a la vez moral y política, forma de desconfiar de las artes de gobernar, de recusarlas, de limitarlas, de transformarlas. Primera definición de esta actitud cuyo peso específico recae en la subjetivación: el arte de no ser de tal modo gobernado, y de no ser gobernado a ese precio, de esa manera. ${ }^{8}$

Y si la gubernamentalización es en efecto el movimiento mediante el cual se trataba, en la realidad de una práctica

8 Este "no querer ser gobernado de tal modo" implica tres puntos de anclaje históricos, que bien pueden comprenderse desde aquello que con anterioridad mencionamos como "problematización", ya que esos anclajes históricos son en relación con la verdad, con el poder y con el sujeto. En cuanto a la verdad, en la medida en que implicaba en aquel momento que el gobierno de los hombres se vinculaba a la autoridad de la Iglesia, por lo tanto, se trataba de cuestionar la interpretación de las Escrituras, es decir, poner en entredicho el dogma. En cuanto al poder, en no querer aceptar las leyes porque son injustas o porque esconden en la figura del soberano una ilegitimidad esencial. La crítica se expresa oponiendo a esa violencia unos derechos universales e imprescriptibles a los cuales todo gobierno debía someterse. Por último, y respecto del sujeto, es no aceptar como verdadero lo que una autoridad nos dice como verdad. Es así que la crítica anuda verdad, poder y sujeto. 
social, de sujetar a los individuos a través de mecanismos de poder que reivindican para sí una verdad, pues bien, yo diría que la crítica es el movimiento por medio del cual el sujeto se atribuye el derecho de interrogar a la verdad sobre sus efectos del poder y al poder sobre sus discursos de verdad; la crítica será el arte de la inservidumbre voluntaria, el de la indocilidad reflexiva. La crítica tendría esencialmente por función la desujeción en el juego de lo que podríamos llamar, en una palabra, la política de la verdad (Foucault, 2018, p. 52).

Foucault habla de "cómo no ser gobernado" y de "un arte de la inservidumbre voluntaria y de la indocilidad reflexiva" (en un contrapunto con la noción de gobierno y de obediencia). Ahora bien, como vemos a partir del análisis, si bien Foucault retoma aspectos de la crítica kantiana, da un nuevo giro en relación a las prácticas de libertad. Mientras para Kant la ilustración se encuentra en la posibilidad de hacer uso público de la razón -donde desde nuestro punto de vista se inaugura algo problemático entre las libertades formales y la obediencia civil, cuestión que, como ya hemos dicho, nos hemos referido en otros trabajos (Vignale, 2018; Vignale y Alvarez, 2018), Foucault destaca una actitud de indocilidad y desobediencia. La división entre uso público y uso privado de la razón, permite a Kant mantenerse en los límites del contrato con aquellos que gobiernan a los otros: la obediencia al soberano es el "uso privado", como el mismo Foucault lo expresa (2018, pp. 83-84). Pero de acuerdo a las definiciones de la actitud crítica foucaulteanas, el germen de las contraconductas $-y$ de la posibilidad de desujecionarse de aquello que se le ha impreso desde técnicas coactivas- reside no sólo en la posibilidad de hacer un uso público de la razón y de ejercer el propio entendimiento sin el tutelaje de otro, sino en una actitud o ethos. Así presentadas las cosas, la crítica es la posibilidad de desobedecer no sólo como una actitud racional, no sólo mediante la libertad formal de decir lo que pienso, sino de tramitar efectivamente la oposición voluntaria al modo en que se es gobernado, una inservidumbre voluntaria, una indocilidad reflexiva. Entra en coalición, desde nuestro punto de 
vista, el mantenerse o no dentro de los límites de las libertades formales, y en cierta medida, una desacralización de la potencia instituyente del derecho en términos de la ley, para destacarse la potencia destituyente de las prácticas de libertad y de la creación de nuevas formas de vida mediante la crítica. Hemos dicho desacralización de la potencia instituyente en términos de derechos, pero el mismo Foucault habla del movimiento por medio del cual el sujeto "se atribuye el derecho" de interrogar a la verdad sobre sus efectos del poder y al poder sobre sus discursos de verdad, para lo cual es necesario comprender lo que

In this light, rights are defined as a practice and as a factual ability to claim rights. Foucault, following Nietzsche, does not treat rights as inherent properties of individuals that then set limits to other individual or collective bodies; rather, he regards rights as a matter of relations between those agents. The new relational right is not defined in terms of legal o formal rights, but rather as an effective right in the sense that it onkly exist when it is recognized and guaranteed by power relations (Lemke, 2012, p. 68). ${ }^{9}$

No se trata exclusivamente, entonces, de un desplazamiento metodológico y epistemológico del objeto al sujeto, sino de una torsión política: entender la crítica como una fuerza a partir de la cual es posible no solamente un uso por parte del entendimiento en su esfuerzo por no extralimitarse de lo que es posible conocer -un problema del siglo XVIII-, sino un uso práctico y político de lo posible. Se puede encontrar aquí el funcionamiento de aquello que proponíamos más arriba respecto del ejercicio crítico: el de problematizar la política, más que el de ofrecerle soluciones. En este sentido,

\footnotetext{
9 "Desde este punto de vista, los derechos se definen como una práctica y como una capacidad fáctica para reclamar derechos. Foucault, siguiendo a Nietzsche, no trata los derechos como propiedades inherentes de los individuos que luego establecen límites a otros cuerpos individuales o colectivos; más bien, considera los derechos como una cuestión de relaciones entre esos agentes. El nuevo derecho relacional no se define en términos de derechos legales o formales, sino más bien como un derecho efectivo en el sentido de que solo existe cuando es reconocido y garantizado por las relaciones de poder" (la traducción es nuestra).
} 
Criticar el gobierno no significa tener que proponer respuestas "razonables" a su agenda de problemas, sino más bien interpelarlo sobre las finalidades que él se concede, sobre los medios elegidos para realizarlas, sobre la propia "razonabilidad" general de los procedimientos y de los motivos con que reviste su propia acción. No es tarea del gobernado, gobernar. (Chignola, 2018, p. 213).

Sandro Chignola apunta algo sobre lo cual es necesario volver: no solicitarle a quienes realizan la crítica que ofrezcan además un programa o imagen del futuro. "No es tarea del gobernado, gobernar", y el quid de la crítica es propiamente el cuestionamiento de las relaciones entre saber y poder, la interrogación por esa razonabilidad de determinadas prácticas de gobierno. Con esto último, puede verse que la función de la crítica no puede asimilarse a una función ordenadora o normativizadora. Por eso "la crítica sólo existe en relación con algo distinto de ella: es instrumento, es medio para un porvenir o una verdad que ella no conocerá y no será; es una mirada sobre un dominio donde sin duda le gusta hacer de policía y donde no es capaz de hacer la ley (Foucault, 2018, p. 46). Por eso una vez más en palabras de Chignola: "La crítica, para Foucault -y creo que esto es decisivo para comprender también su análisis de la gubernamentalización del poder-, no debe legislar. No dice lo que se debe hacer" (2018, p. 202).

Por otra parte, es relevante destacar aquí aquello que se menciona como la "desujeción de una política de la verdad", en cuanto interviene la posibilidad de modificar la relación entre el sujeto y lo que de antemano se ha establecido como verdadero. Doble juego, a la vez político y epistemológico, cuya injerencia filosófica no es teórica, sino práctica. La actitud crítica convoca una libertad que cuestiona lo establecido, y aunque no convoque a la obediencia -como en la gestión de los usos público y privado de la razón-, no por ello es un proceso irracional. Por otra parte, el riesgo que comporta la actitud crítica no es tanto el de las desobediencias como el de poner en juego la propia constitución subjetiva. Deviniendo formador de sí mismo, el 
sujeto se arriesga a sí mismo en su formación, pero a través de una estética de sí o de la capacidad de transformarse a sí mismo en ese desanudamiento de la coacción a determinado juego entre verdad y poder. Como lo señala Judith Butler,

El yo se forma a sí mismo, pero se forma a sí mismo dentro de una serie de prácticas formativas que Foucault caracteriza como modos de subjetivación. Que la paleta de sus formas posibles esté delimitada de antemano por dichos modos de subjetivación no significa que el yo no consiga formarse a sí mismo, que el yo esté totalmente formado. Al contrario, se le obliga a formarse, pero formarse a sí mismo en formas que ya están más o menos operando y en proceso. O, podría decirse, se le obliga a formarse dentro de prácticas que ya están más o menos funcionando. Pero si esa formación de sí se hace en desobediencia a los principios de acuerdo con los cuales una se forma, entonces la virtud se convierte en la práctica por la cual el yo se forma a sí mismo en desujeción, lo que quiere decir que arriesga su deformación como sujeto, ocupando esa posición ontológicamente insegura que plantea otra vez la cuestión: quién será un sujeto aquí y qué contará como vida; un momento de cuestionamiento ético que requiere que rompamos los hábitos de juicio en favor de una práctica más arriesgada que busca actuar con artisticidad en la coacción (2001).

De modo que, con la actitud crítica, Foucault expresa la propia intervención en la formación de nosotros mismos, completando la idea de artes de la vida y estéticas de la existencia que son la hipérbole de su anti-fundacionalismo, aunque no por ello una ética de lo individual, un puro esteticismo desinteresado o una práctica anárquica en la formación de sí consigo, como en algunos casos ha sido interpretado. No se trata de una estetización a costa de lo político, sino por el contrario, de encarar lo político desde lo ético, involucrando el sí mismo en las estrategias de gobierno, y de ofrecer por medio de este ethos las posibilidades de resistencias al poder político. 
Retomando la idea del cuestionamiento de las relaciones entre saber y poder, Foucault encara de otra forma el problema que ya había sido formulado por la Escuela de Frankfurt, a propósito de su "teoría crítica": que es en la razón misma donde hay que buscar los excesos de poder, sobre todo del proyecto moderno que la enarbolaba como la garante del progreso, cuestión que los frankfurtianos desnudaron a partir de la crítica al positivismo, el objetivismo y de la tecnificación, desenmascarando una visión ingenua de la ciencia y mostrando los modos de dominación sociales y políticos. Por su parte, Foucault habla de la crítica como una práctica histórico-filosófica (que no es una filosofía de la historia, ni una historia de la filosofía) que tiene por objeto las "relaciones entre las estructuras de racionalidad que articulan el discurso veraz y los mecanismos de sujeción ligados a él" (2018, p. 61-62). En otras palabras, las relaciones entre sujeto y verdad, o como hemos referido antes, la posibilidad de estudiar la emergencia conjunta de modos de objetivación y modos de sujeción.

\section{Concluyendo}

Hemos trabajado en torno a la cuestión de la crítica desde una perspectiva filosófica, abordándola como método de trabajo teórico, pero también como un ethos o actitud, de implicancias subjetivas.

En cuanto aporte para las metódicas en las ciencias humanas y sociales, nos resultó relevante la necesidad de decir que no tenemos que negociar con los fórceps metodológicos preestablecidos para nuestras disciplinas. Sin lugar a dudas hay estrategias cualitativas y cuantitativas que son eficaces para determinadas investigaciones, pero el "método" no se reduce a ellas, sino que puede haber tantas metódicas como objetos de estudio. En segundo lugar, frente a una concepción de la producción del conocimiento que sostiene la neutralidad valorativa, nos posicionamos en una epistemología crítica, que atiende las condiciones históricas y políticas de emergencia conjunta de sujetos y objetos. Sobre esta última consideración es que abordamos el trabajo 
de Foucault, puesto que, con ese desplazamiento de una crítica trascendental a una crítica histórica, ha realizado una gran contribución sobre nuestros modos de trabajo. ${ }^{10}$

Sobre una caracterización de qué no es la crítica, dijimos que no puede pensarse -tal vez como corrientemente se piensaque se trata de forma de rechazo o de descalificación, de un ejercicio de la polémica, aunque tampoco con una forma de análisis a partir del cual se encontraría la mejor solución. La crítica no dice qué es lo que se debe hacer, tarea propia de la política. Sería confundir los ámbitos del gobierno y de cómo no ser gobernados de la manera en que somos gobernados, lo que hemos mostrado gracias a una genealogía de la crítica como una actitud.

Hemos delimitado el trabajo de la crítica a partir de la consideración de los a priori históricos de una experiencia posible: es decir, a partir de hacer confluir en el análisis histórico la relación entre formas de veridicción, procedimientos de gubernamentalidad y formas de relación de sí consigo, en rechazo de universales y trascendentales, y con atención a la llegada de lo inédito, de la apertura a futuros que no son posibles de legislar de manera anticipada, puesto que la crítica no legisla ni gobierna. Una prueba bistórico-práctica de los límites que podemos franquear, dijimos, y en ese sentido, hemos considerado la crítica como un ethos, como el trabajo de nosotros mismos sobre nosotros mismos en nuestra condición de seres libres.

Sobre el ejercicio de la crítica, dijimos que se trata de la posibilidad de plantear un problema a la política, lo que Foucault define con el nombre de "problematización": interpelar a la política sobre sus discursos de verdad, sobre su propia razonabilidad. De manera que esa es la realción que la crítica

\footnotetext{
10 Pensábamos, por ejemplo, cómo el trabajo con a priori históricos de una experiencia posible, y en general ese ejercicio de problematización a la política, ha permitido avanzar con una labor más "microfísica" en las relaciones entre el poder y la vida, pudiendo mostrar cómo la historia alcanza y determina a las vidas singulares 0 , dicho de otro modo, cómo la historia se pliega en las biografías, como puede encontrarse en los trabajos de Didier Eribon (2019) 0 Didier Fassin -que trabaja en el cruce del trabajo genealógico y la etnografía- (2018a, 2018b), y en otro sentido también el trabajo de Judith Butler sobre "vidas precarias" (2017).
} 
tiene con el problema del gobierno, como forma de resistencia política, como voluntad de no ser gobernados de esta manera, atribuyéndose los sujetos, y gracias a ella, el derecho de interrogar a la verdad sobre sus efectos del poder y al poder sobre sus discursos de verdad.

Finalmente, trabajamos sobre las implicancias subjetivas de la crítica, en cuanto el tipo de análisis busca determinar lo que queremos aceptar, rechazar, o cambiar de nosotros mismos en nuestra actualidad. Tal y como lo hemos presentado, la actitud crítica sortea el problema de las libertades formales y la obediencia civil -algo que en la respuesta kantiana a la Ilustración es ambiguo-, presentándose como actitud de indocilidad y de desobediencia, que no se reduce a una actitud racional o a la libertad formal de decir lo que pienso, sino de tramitar efectivamente la oposición voluntaria al modo en que se es gobernado, una inservidumbre voluntaria, una indocilidad reflexiva. La desujeción de una politica de la verdad es el quid de las resistencias políticas que plantea la crítica como actitud: en cuanto interviene la posibilidad de modificar la relación entre el sujeto y lo que de antemano se ha establecido como verdadero, y cuyo riesgo parresiástico pasa por poner en juego la propia constitución subjetiva, por el desanudamiento de la configuración de una experiencia que necesariamente invita a una nueva invención subjetiva, y a plantear la pregunta ¿cómo ser otros de los que somos?

\section{Bibliografía}

AGAMBEN, Giorgio (2019). ¿Qué es real? La desaparición de Majorana. Buenos Aires: Adriana Hidalgo.

AGAMBEN, Giorgio (2018). Signatura rerum. Sobre el método. Buenos Aires, Adriana Hidalgo.

AGAMBEN, Giorgio (2017). El uso de los cuerpos. Buenos Aires, Adriana Hidalgo.

BUTLER, Judith (2017). Cuerpos aliados y lucha politica. Hacia una teoría performativa de la asamblea. Ciudad Autónoma de Buenos Aires, Paidós. 
BUTLER, Judith (2001). ¿Qué es la crítica? Un ensayo sobre la virtud de Foucault. En: Instituto europeo para políticas culturales progresivas, Mayo 2001.Recuperado de http://eipcp.net/transversal/0806/butler/es. Trad. Marcelo Expósito.

DÍAZ, Esther (2000). La posciencia. El conocimiento científico en las postrimerías de la modernidad. Buenos Aires, Biblos.

ERIBON, Didier (2019). Principios de un pensamiento crítico. Buenos Aires, El cuenco de plata.

FASSIN, Didier (2018a). Castigar. Una pasión contemporánea. Ciudad Autónoma de Buenos Aires, Adriana Hidalgo.

FASSIN, Didier (2018b). Por una repolitización del mundo. Las vidas descartables del siglo XXI. Ciudad Autónoma de Buenos Aires, Siglo XXI.

CHIGNOLA, Sandro (2018). Foucault, más allá de Foucault. Una politica de la filosofía. Ciudad Autónoma de Buenos Aires, Cactus.

FOUCAULT, Michel (2004). La arqueología del saber. Buenos Aires, Siglo XXI.

FOUCAULT, Michel. (2010a). Foucault. En: Obras esenciales. Madrid: Paidós.

FOUCAULT, Michel (2009). El Gobierno de sí y de los otros. Curso en el Collège de France 1982-1983. Buenos Aires, Fondo de Cultura Económica.

FOUCAULT, Michel (2001). La hermenéutica del sujeto. Curso en el Collège de France 1981-1982. Buenos Aires, Fondo de Cultura Económica.

FOUCAULT, Michel (2008). Historia de la sexualidad 2: El uso de los placeres. Buenos Aires, Siglo XXI.

FOUCAULT, Michel. (2010b). Polémica, política y problematizaciones. En: Obras esenciales. Madrid: Paidós.

FOUCAULT, Michel (2018). ¿Qué es la crítica? Seguido de La cultura de sí. Buenos Aires, Siglo XXI.

FOUCAULT, Michel. (2010c). ¿Qué es la Ilustración? En: Obras esenciales. Madrid: Paidós.

FOUCAULT, Michel. (2010d). La verdad y las formas jurídicas. En: Obras esenciales. Madrid: Paidós.

KANT, Immanuel (2008). Crítica de la razón pura. México, Porrúa. 
KANT, Immanuel (2013). ¿Qué es la Ilustración? y otros escritos de ética, política y filosofía de la historia. Madrid, Alianza.

LEMKE, Thomas (2012). Foucault, governmentality, and critique. Boulder, Paradigm Publishers.

SAMAJA, Juan (2000). Semiótica y Dialéctica. Buenos Aires, JVE.

VIGNALE, Silvana (2019). Ciencias sociales y principio de incertidumbre. BORDES, agosto-octubre de 2019, año 4 número 14, ISSN 2524-9290, pp. 41-47. Recuperado a partir de https:// publicaciones.unpaz.edu.ar/OJS/index.php/bordes/article/ view/553

VIGNALE, Silvana (2013). "Foucault, actitud crítica y subjetivación". Cuadernos de Filosofía. Nro. 61. Buenos Aires, Primavera 2013. Instituto de Filosofía, Universidad de Buenos Aires. ISSN 05901901 (impreso)ISSN 2362-485x (en línea). Pp. 5-17. http:// revistascientificas.filo.uba.ar/index.php/CdF/article/view/2440

VIGNALE, Silvana (2018). Ilustración y uso prudente de la razón, hacia una actualización desobediente de la crítica. En: Revista Barda: Posfordismo, sociedades de control y neoliberalismo. Año 4, Nro. 6, 2018. Centro de Estudios de Filosofía de la Cultura, Universidad Nacional de Comahue. Pp. 117.131.ISSN 2469-1135. En línea: http://www.cefc.org.ar/revista/index. php/portfolio-item/numero-6-julio-2018/;

VIGNALE, Silvana (2017a). Neoliberalismo, presente y subjetivación: hacia nuevas formas de lo crítico. Revista El Arco y la Lira. Tensiones y debates filosóficos. Número 5. Dossier: Revisitando la crítica foucaulteana al neoliberalismo. ISSN 2344-9292. PP. 17-28. https://www.revistaarcoylira.com.ar/ copia-de-numero-4.

VIGNALE, Silvana (2017b). "Notas epistemológicas sobre las relaciones entre sujeto y verdad: el cuerpo como inquietud". En: Ambrosini, Cristina, Andrés Mombru y Pablo Méndez (comp.) (2017). Tradiciones y rupturas. Modulaciones epistemológicas IV. El escenario argentino e iberoamericano. De la UNLa.

VIGNALE, Silvana y Luciana Alvarez (2018). Prácticas de libertad en la gubernamentalidad neoliberal: claves para pensar la desobediencia en los bordes del sujeto. XI Coloquio Internacional Michel Foucault "Foucault e as praticas da libertade" (Florianópolis, 2018). 